\title{
The radiological evaluation of the nasal cavity, conchae and nasal septum volumes by stereological method: A retrospective cone-beam computed tomography study
}

\author{
Begumhan Turhan ${ }^{1, A-E}$, Piraye Kervancioglu ${ }^{2, A, C-E}$, Eda Didem Yalcin ${ }^{3, A-D}$ \\ ${ }^{1}$ Department of Physiotherapy and Rehabilitation, Faculty of Health Sciences, Hasan Kalyoncu University, Gaziantep, Turkey \\ 2 Department of Anatomy, Faculty of Medicine, Gaziantep University, Turkey \\ ${ }^{3}$ Department of Dentomaxillofacial Radiology, Faculty of Dentistry, Gaziantep University, Turkey \\ A - research concept and design; $\mathrm{B}$ - collection and/or assembly of data; $\mathrm{C}$ - data analysis and interpretation; \\ $D$ - writing the article; $E$ - critical revision of the article; $F$ - final approval of the article
}

Address for correspondence

Begumhan Turhan

E-mail: begum.aliosmanoglu@hku.edu.tr

Funding sources

None declared

Conflict of interest

None declared

Received on July 27, 2018

Reviewed on September 27, 2018

Accepted on 0ctober 15, 2018

Published online on April 13, 2019

Cite as

Turhan B, Kervancioglu P, Yalcin ED. The radiological evaluation of the nasal cavity, conchae and nasal septum volumes by stereological method: A retrospective conebeam computed tomography study. Adv Clin Exp Med. 2019;28(8):1021-1026. doi:10.17219/acem/98960

DOI

10.17219/acem/98960

Copyright

Copyright by Author(s)

This is an article distributed under the terms of the

Creative Commons Attribution Non-Commercial License

(http://creativecommons.org/licenses/by-nc-nd/4.0/)

\section{Abstract}

Background. The nasal cavity (NC) is the entrance to the respiratory system. Many studies have been conducted on the structure, function and volume of the NC. Only a few studies were performed assessing the volumetric values of $\mathrm{NC}$ and conchae.

Objectives. The aim of this study was to evaluate the volumetric measurements of the NC, conchae and nasal septum using the stereological method.

Material and methods. Cone-beam computed tomography (CBCT) images of 200 individuals (100 females and 100 males) aged 8-59 years were retrospectively evaluated. Inferior nasal concha and middle nasal concha, NC and nasal septum volumes were measured on these images. Measurements were made using point counting method, which is based on the Cavalieri principle. The mean values of the measured structures for 2 age groups and for each gender were obtained. Differences between the groups and genders of all parameters were examined. The volume fractions of measured volumes were calculated.

Results. The mean volumes of the nasal septum, left and right NC, left and right inferior nasal conchae, and left and right middle nasal conchae were $4.99 \pm 1.51 \mathrm{~cm}^{3}, 7.44 \pm 2.93 \mathrm{~cm}^{3}, 7.68 \pm 2.99 \mathrm{~cm}^{3}, 3.10 \pm 1.11 \mathrm{~cm}^{3}$, $3.04 \pm 1.02 \mathrm{~cm}^{3}, 1.32 \pm 0.56 \mathrm{~cm}^{3}$, and $1.28 \pm 0.49 \mathrm{~cm}^{3}$, respectively. Gender and age differences were statistically significant in all volumes $(p<0.05)$.

Conclusions. The data obtained in this study may assist clinicians in planning treatment, assessing the treatment results of pathological conditions within the NC, and help surgeons in preoperational and postoperational evaluations, especially in dentistry, otorhinolaryngology and plastic surgery.

Key words: Cavalieri principle, stereology, nasal cavity volume, cone-beam computed tomography 


\section{Introduction}

The nasal cavity (NC) is the first part of the respiratory system. It opens posteriorly into the nasopharynx through the choanae and the anterior openings are nares. The NC is divided into 2 parts with a compartment which is called the nasal septum. Conchae are prominent bony structures on both lateral walls of the $\mathrm{NC}$, which are covered with mucosa. Also, the conchae are dynamic structures because the area where they are located has the thickest mucous membrane of the NC and intense vascularization. The dynamic nature of the conchae allows the air flow rate and the amount of air to be adjusted. 6,26,27 The volumes of the mentioned structures can be calculated with cross-sectional tomography images using the stereological methods.

Stereological methods provide numerical data, such as volumes, surface areas, as well as densities and lengths of structures objectively and efficiently. ${ }^{10,16}$ The Cavalieri principle, a stereological method, is effective in volumetric measurements of anatomical structures. In this principle, parallel and equally thick sections of a structure are taken, the total of section areas multiply by the thickness of section and the volume of the structure is calculated. It is accepted that the Cavalieri principle is the gold standard and provides realistic measurements. ${ }^{1,2}$

The sectional images obtained with conventional computed tomography (CT) and magnetic resonance imaging (MRI) can be used in the calculation of the volume of a structure using the Cavalieri principle. ${ }^{13}$ There are only few quantitative studies of NC volumetric analysis performed with cone-beam computed tomography (CBCT).

The most important advantage of CBCT is that the practitioner can obtain 3-dimensional images in sagittal, axial and coronal planes. Three-dimensional reconstruction of CBCT images is also possible. This imaging technique provides valuable information to clinicians and researchers. ${ }^{23,31}$

There is no published study about analyzing the volumes of the NC, conchae and nasal septum using CBCT images with stereological method. In this study, we aimed to calculate the volumes of all these structures on CBCT images with the stereological method.

\section{Material and methods}

\section{Samples}

Patients, admitted to Gaziantep University Faculty of Dentistry in Department of Dentomaxillofacial Radiology for computed tomography examination between January 2015 and February 2017, were retrospectively evaluated. All of the patients had been referred for the diagnosis and treatment planning because of different problems involving the dentomaxillofacial region. All CBCT images were obtained in the sitting position (scanning time: 14-18 s, collimation height: $13 \mathrm{~cm}$ and voxel size: $0.4 \mathrm{~mm}$ ) using the same device (Planmeca ProMax 3D Mid; Planmeca, Helsinki, Finland). Age groups were established in order to show the differences between the measurements of adults and children. The age limit of 18 years was taken into account which is important for the development and the rapid growth. Images on axial, coronal and sagittal planes of 100 female (50 adults, 50 under 18 years of age) and 100 male (50 adults, 50 under 18 years of age) individuals without craniofacial anomalies and artifacts were evaluated (Fig. 1).

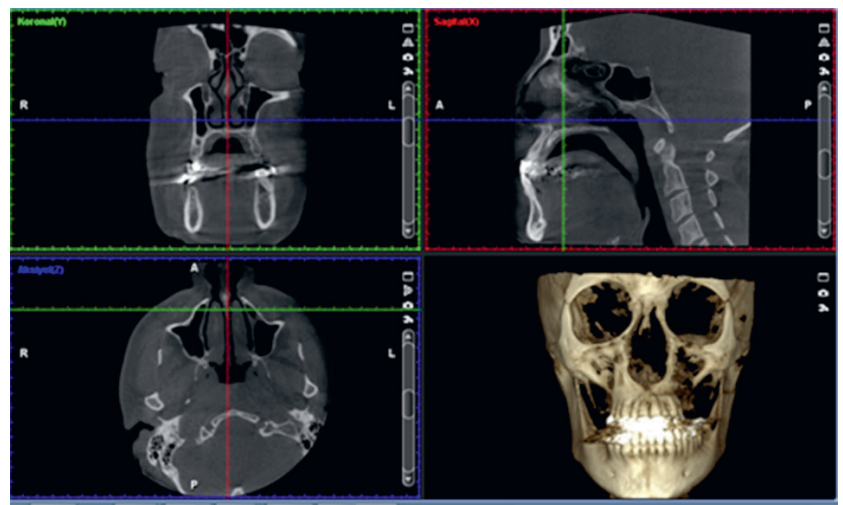

Fig. 1. Display of structures - cone-beam computed tomography (CBCT) in sagittal, axial and coronal planes and 3D reformatted image

\section{Procedures}

A computer-assisted stereological analysis system (StereoInvestigator v. 8.0, MicroBrightField Bioscience, Williston, USA) was used for the measurements. Ethical approval was obtained from the ethical committee of Gaziantep University (ethics committee decision No: 111/6, date of approval: 12.02.2016).

Volumetric estimations were determined on the coronal images using point-counting (Cavalieri method) approach within stereological methods. All measurements were performed by the same researcher. The volumes of the right and left nasal cavities (RNCV and LNCV) were calculated from the air-filled areas, except for the soft tissue and bony structures. The right and left inferior nasal conchae volumes (RINCV and LINCV), right and left middle nasal conchae volumes (RMNCV and LMNCV) and nasal septum volume (NSV) were calculated from the bony structures and the soft tissue lying over them (Fig. 2).

The volume fraction $(\mathrm{Vv})$ representing the proportion of a component in the whole structure was calculated. The volume ratio of each component to the total volume (TV) was determined as a percentage (\%).

The volume fraction formula can be written as follows:

$$
\mathrm{Vv}(\mathrm{a}, \mathrm{b})=\frac{\Sigma a}{\Sigma b} \times 100
$$

(a: each of the components, b: total volume $)^{17}$ 


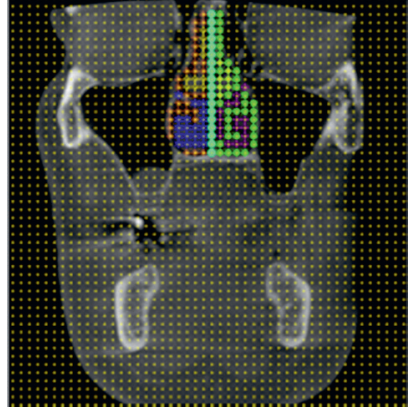

Fig. 2. Calculating the volumes of structures using point counting method

We estimated the volume fraction of the middle nasal conchae, inferior nasal conchae and nasal septum within the TV (RINCV + LINCV + RMNCV + LMNCV + NSV $+\mathrm{RNCV}+\mathrm{LNCV}$ ) with the volume fraction approach, i.e., the MNC volume within the TV volume using the following formula:

$$
\begin{gathered}
\mathrm{Vv} \text { (middle nasal conchae, total volume })= \\
=\frac{\text { Emiddlenasalconchae }}{\sum \text { totalvolume }} \times 100
\end{gathered}
$$

\section{Statistical analysis}

The data was evaluated using SPSS v. 22.0 for Windows (IBM Corp., Armonk, USA) and by analyzing descriptive statistics (frequency, mean and standard deviation (SD)). Before the statistical analysis, Shapiro-Wilk test was used to test for normal distribution of data. All continuous variables were normally distributed. Independent sample $\mathrm{t}$-tests were used to compare the groups. A p $<0.05$ was considered statistically significant.

\section{Results}

The mean age of all individuals, females and males was $26.00 \pm 15.34,24.80 \pm 14.69$ and $27.21 \pm 15.95$, respectively (Table 1).

Mean RNCV, LNCV, RINCV, LINCV, RMNCV, $L M N C V$, and NS values of all subjects were $7.68 \pm 2.99 \mathrm{~cm}^{3}$, $7.44 \pm 2.93 \mathrm{~cm}^{3}, 3.04 \pm 1.02 \mathrm{~cm}^{3}, 3.10 \pm 1.11 \mathrm{~cm}^{3}, 1.28 \pm 0.49 \mathrm{~cm}^{3}$, $1.32 \pm 0.56 \mathrm{~cm}^{3}$, and $4.99 \pm 1.51 \mathrm{~cm}^{3}$, respectively.

The mean volumes of measured structures of female and male subjects are represented in Table 2 . The NC and nasal septum volumes of males were larger than those of females $(\mathrm{p}<0.05)$. On the other hand, there was a significant

Table 1. Mean ages in respective groups. Values are given as mean \pm standard deviation (SD)

\begin{tabular}{|l|c|c|c|c|} 
Parameter & $\begin{array}{c}\text { Female } \\
\text { adults }\end{array}$ & $\begin{array}{c}\text { Female } \\
\text { children }\end{array}$ & Male adults & $\begin{array}{c}\text { Male } \\
\text { children }\end{array}$ \\
\hline Age [years] & $36.52 \pm 12.23$ & $13.08 \pm 2.45$ & $41.00 \pm 10.90$ & $13.42 \pm 2.66$ \\
\hline
\end{tabular}

Table 2. Mean volumes of structures in different gender $(n=200$ for each structure)

\begin{tabular}{|l|c|c|c|}
\multicolumn{1}{|c|}{ Structure } & Males ${ }^{\mathrm{a}}\left[\mathrm{cm}^{3}\right]$ & Females $^{\mathrm{a}}\left[\mathrm{cm}^{3}\right]$ & $p$-value \\
\hline RNC $\left[\mathrm{cm}^{3}\right]$ & $9.24 \pm 2.86$ & $6.13 \pm 2.22$ & 0.001 \\
\hline LNC $\left[\mathrm{cm}^{3}\right]$ & $8.78 \pm 3.00$ & $6.09 \pm 2.17$ & 0.001 \\
\hline RINC $\left[\mathrm{cm}^{3}\right]$ & $3.42 \pm 0.95$ & $2.67 \pm 0.95$ & 0.001 \\
\hline LINC $\left[\mathrm{cm}^{3}\right]$ & $3.44 \pm 1.11$ & $2.76 \pm 1.01$ & 0.001 \\
\hline RMNC $\left[\mathrm{cm}^{3}\right]$ & $1.41 \pm 0.47$ & $1.14 \pm 0.46$ & 0.001 \\
\hline LMNC $\left[\mathrm{cm}^{3}\right]$ & $1.43 \pm 0.54$ & $1.21 \pm 0.55$ & 0.004 \\
\hline NS $\left[\mathrm{cm}^{3}\right]$ & $5.69 \pm 1.05$ & $4.29 \pm 1.57$ & 0.001 \\
\hline
\end{tabular}

a Values are given as mean \pm standard deviation (SD); ${ }^{b}$ statistical difference between genders ( $p<0.05$ : significant); RNC - right nasal cavity; LC - left nasal cavity; RINC - right inferior nasal concha; LINC - left inferior nasal concha; RMNC - right medial nasal concha; LMNC - left medial nasal concha; NS - nasal septum.

Table 3. Mean volumes of structures in adults and children

\begin{tabular}{|l|c|c|c|}
\multicolumn{1}{|c|}{ Structure } & $\begin{array}{c}\text { Adults } \\
(\mathrm{n}=180)\end{array}$ & $\begin{array}{c}\text { Children }^{\mathrm{a}} \\
(\leq 18 \text { years })(\mathrm{n}=100)\end{array}$ & p-value $^{\mathrm{b}}$ \\
\hline RNC $\left[\mathrm{cm}^{3}\right]$ & $9.08 \pm 3.17$ & $6.28 \pm 2.00$ & 0.001 \\
\hline LNC $\left[\mathrm{cm}^{3}\right]$ & $8.79 \pm 3.11$ & $6.08 \pm 1.98$ & 0.001 \\
\hline RINC $\left[\mathrm{cm}^{3}\right]$ & $3.36 \pm 0.93$ & $2.73 \pm 1.01$ & 0.001 \\
\hline LINC $\left[\mathrm{cm}^{3}\right]$ & $3.51 \pm 0.96$ & $2.68 \pm 1.10$ & 0.001 \\
\hline RMNC $\left[\mathrm{cm}^{3}\right]$ & $1.49 \pm 0.48$ & $1.15 \pm 0.57$ & 0.001 \\
\hline LMNC $\left[\mathrm{cm}^{3}\right]$ & $1.43 \pm 0.47$ & $1.12 \pm 0.46$ & 0.001 \\
\hline NS $\left[\mathrm{cm}^{3}\right]$ & $5.62 \pm 1.66$ & $4.35 \pm 0.99$ & 0.001 \\
\hline
\end{tabular}

a Values are given as mean \pm standard deviation (SD); ${ }^{\mathrm{b}}$ statistical difference between genders ( $p<0.05$ : significant); RNC - right nasal cavity; LC - left nasal cavity; RINC - right inferior nasal concha; LINC - left inferior nasal concha; RMNC - right medial nasal concha; LMNC - left medial nasal concha; NS - nasal septum.

difference between the inferior nasal concha volumes of male and female subjects $(p<0.05)$. Also, there was a significant difference between the 2 genders regarding middle nasal concha volumes $(\mathrm{p}<0.05)$ (Table 2$)$.

The mean volumes of measured structures in adults and children are shown in Table 3. The nasal cavities of adults were larger than those of children $(\mathrm{p}<0.05)$. Also, the volumes of all structures were larger in adults $(\mathrm{p}<0.05)$.

There was no statistically significant difference between the right and the left $\mathrm{NC}$ volumes of all individuals $(p=0.07)$. Also, there was no statistically significant difference between the right and the left middle and inferior nasal conchae volumes $(\mathrm{p}=0.247$ and $\mathrm{p}=0.449$, respectively).

The volume fractions (\%) of structures in total NC volume are shown in Table 4.

\section{Discussion}

Many studies have been conducted on the structure, function and volume of the NC. In these studies, the structures of the NC, conchae and meatuses, anatomical variations, and air flow in the $\mathrm{NC}$ were examined. Radiological imaging, 
Table 4. Volume fractions of structures in total volume according to age and gender. Values are given as mean \pm standard deviation (SD)

\begin{tabular}{|l|c|c|c|c|}
\multicolumn{1}{|c|}{ Volume fraction } & Female adults [\%] & Female children [\%] & Male adults [\%] & Male children [\%] \\
\hline RINCV/TV $\left[\mathrm{cm}^{3}\right]$ & $10.59 \pm 2.65$ & $11.01 \pm 2.77$ & $9.59 \pm 1.82$ & $11.11 \pm 2.82$ \\
\hline LINCV/TV $\left[\mathrm{cm}^{3}\right]$ & $11.38 \pm 2.50$ & $11.38 \pm 3.35$ & $10.10 \pm 1.89$ & $10.56 \pm 3.38$ \\
\hline RMNC/TV $\left[\mathrm{cm}^{3}\right]$ & $4.76 \pm 1.75$ & $4.94 \pm 1.74$ & $4.10 \pm 0.86$ & $4.46 \pm 1.41$ \\
\hline LMNC/TV [cm $\left.{ }^{3}\right]$ & $5.01 \pm 1.53$ & $4.97 \pm 2.05$ & $4.17 \pm 1.01$ & $4.50 \pm 1.68$ \\
\hline NSV/TV $\left[\mathrm{cm}^{3}\right]$ & $16.81 \pm 3.14$ & $19.56 \pm 3.43$ & $17.68 \pm 4.72$ & $16.91 \pm 2.07$ \\
\hline RNCV/TV $\left[\mathrm{cm}^{3}\right]$ & $25.48 \pm 3.81$ & $24.13 \pm 4.27$ & $28.02 \pm 3.09$ & $26.91 \pm 3.45$ \\
\hline LNCV/TV $\left[\mathrm{cm}^{3}\right]$ & $25.58 \pm 4.10$ & $23.97 \pm 3.91$ & $26.31 \pm 3.77$ & $25.52 \pm 3.98$ \\
\hline
\end{tabular}

TV - total volume; RINCV - right inferior nasal concha volume; LINCV - left inferior nasal concha volume; RMNC - right middle nasal concha volume; LMNC - left middle nasal concha volume; NSV - nasal septum volume; RNCV - right nasal cavity volume; LNCV - left nasal cavity volume.

dissection, measurements on dry bone, acoustic rhinometry, and rhinomanometry methods were used. , $^{5,14,20,22,28}$

Terheyden et al. ${ }^{29}$ accepted that the CT is the gold standard for measuring the NC and its components. Low radiation exposure, multiple display modes in combination with high accurate images, thin thickness of slices, real size analysis, and minimal superimposition make the CBCT ideal for the evaluation of the NC.9,12,30 The CBCT allows not only the "real-time" images in the axial plane but also 2-dimensional images in the sagittal, coronal and even oblique or curved image planes. ${ }^{23}$ Despite the lower cost and less radiation dose compared to conventional CT, studies on CBCT images about calculating the volume of $\mathrm{NC}$ and its structures are limited in number.

There are studies that examined some changes before and after rapid maxillary expansion treatment using the CBCT images. ${ }^{3,4,25,32}$ In these studies, skeletal changes, changes in the all upper airway volumes, oropharyngeal volume, mandibular position, respiratory performance, and airway resistance were discussed and data obtained from CBCT images was evaluated with 3D software.
In literature, only 2 studies evaluated the volumetric changes of the $\mathrm{NC}$ using the stereological method on $\mathrm{CT}$ images. ${ }^{6,7}$ Also, these studies researched the changes in structures visible on CT images. In this study, we used CBCT images, where the resolution is better than the resolution of CT images.

Emirzeoğlu et al. ${ }^{6}$ worked on individuals who were $18-$ 40 years old. Ertekin et al. ${ }^{7}$ studied children $8-11$ years of age. We conducted this study on a wide range of age groups (8-59 years of age), including the age range of both mentioned studies. This study is a reference study in Turkish population, where wide-scale volumetric calculations are made using stereological method. Also, the volume of the nasal septum was evaluated in this study, unlike in the study conducted by Emirzeoğlu et al. ${ }^{6}$

Ertekin et al. ${ }^{7}$ and Emirzeoğlu et al. ${ }^{6}$ used CT images with a cross-sectional thickness of $0.6 \mathrm{~mm}$ and $3 \mathrm{~mm}$, respectively. Unlike these 2 studies, we examined a $0.4 \mathrm{~mm}$ slice of thickness on CBCT images. The mean volumes of structures measured in mentioned studies are given in Table 5 as a comparison of literature.

Table 5. Comparision of literature

\begin{tabular}{|c|c|c|c|c|c|}
\hline Parameter & \multicolumn{2}{|c|}{ Ertekin et al. ${ }^{1}$} & Emirzeoğlu et al. ${ }^{35}$ & \multicolumn{2}{|c|}{ This study } \\
\hline Age interval [years] & \multicolumn{2}{|c|}{$8-11$} & $18-40$ & \multicolumn{2}{|c|}{$8-59$} \\
\hline Number of cases & \multicolumn{2}{|c|}{342} & 60 & \multicolumn{2}{|c|}{200} \\
\hline $\mathrm{NCV}\left[\mathrm{cm}^{3}\right]$ & $\begin{array}{c}\mathrm{R} \\
\mathrm{F}: 0.32-1.79 \\
\mathrm{M}: 0.45-2.19 \\
\text { (min-max) }\end{array}$ & $\begin{array}{c}L \\
F: 0.31-1.85 \\
\text { M: 0.45-2.20 } \\
\text { (min-max) }\end{array}$ & $\begin{array}{c}F: 5.95 \pm 0.10 \\
M: 7.01 \pm 0.18 \\
\left(4.10-12.71 \mathrm{~cm}^{3}\right) \\
(\min -\max )\end{array}$ & $\begin{array}{c}R \\
F: 6.13 \pm 2.22 \\
M: 9.24 \pm 2.86\end{array}$ & $\begin{array}{c}L \\
F: 6.09 \pm 2.17 \\
M: 8.78 \pm 3.00\end{array}$ \\
\hline INCV $\left[\mathrm{cm}^{3}\right]$ & $\begin{array}{c}R \\
F: 0.07-0.68 \\
M: 0.09-0.71 \\
\text { (min-max) }\end{array}$ & $\begin{array}{c}L \\
F: 0.08-0.54 \\
\text { M: 0.08-0.70 } \\
\text { (min-max) }\end{array}$ & $\begin{array}{c}F: 1.45 \pm 0.68 \\
M: 1.59 \pm 0.98 \\
(0.41-3.94) \\
(\min -\max )\end{array}$ & $\begin{array}{c}R \\
F: 2.67 \pm 0.95 \\
M: 3.42 \pm 0.95\end{array}$ & $\begin{array}{c}L \\
F: 2.76 \pm 1.01 \\
M: 3.44 \pm 1.11\end{array}$ \\
\hline $\mathrm{MNCV}\left[\mathrm{cm}^{3}\right]$ & $\begin{array}{c}R \\
F: 0.03-0.25 \\
M: 0.04-0.30 \\
\text { (min-max) }\end{array}$ & $\begin{array}{c}L \\
F: 0.03-0.25 \\
\text { M: } 0.04-0.30 \\
\text { (min-max) }\end{array}$ & $\begin{array}{c}F: 0.56 \pm 0.22 \\
M: 0.67 \pm 0.31 \\
(0.25-1.29) \\
(\min -\max )\end{array}$ & $\begin{array}{c}R \\
F: 1.14 \pm 0.46 \\
M: 1.41 \pm 0.47\end{array}$ & $\begin{array}{c}L \\
F: 1.21 \pm 0.55 \\
M: 1.43 \pm 0.54\end{array}$ \\
\hline $\mathrm{NSV}\left[\mathrm{cm}^{3}\right]$ & & & - & & \\
\hline
\end{tabular}

R - right; L - left; F - female; M - male; NSV - nasal septum volume; NCV - right nasal cavity volume; INCV - inferior nasal concha volume; MNC - right middle nasal concha volume. 
Similarly as Emirzeoglu et al. ${ }^{6}$ and Ertekin et al., ${ }^{7}$ we reported that a significant difference between male and female subjects in the NC measurements. We detected, as in these 2 studies, that the males' NC volumes and other structures' volumes in $\mathrm{NC}$ were greater than those in females. According to the obtained data, no significant difference was found in size between the right and left parts of the NC and the conchae.

It is known that nasal conchae are dynamic structures on the lateral wall of the NC. The changes in their sizes and variations of these structures give rise to various clinical consequences. For example, inferior nasal conchae hypertrophy is a kind of variation seen in conchae, resulting in nasal obstruction. ${ }^{24}$ Patients with nasal obstruction have difficulties in breathing in general or mouth breathing and suffer from drying in the throat and mouth, sleeping disorders with snoring, and sometimes apnea. ${ }^{18}$ Another variation that causes nasal obstruction is the paradoxical development of the middle nasal conchae. The paradoxical middle nasal conchae is defined as the lateral inclination of middle nasal conchae. This condition may cause recurrent infundibular disease when it occurs with ethmoid bulla and uncinate process variations. ${ }^{19}$ Also, it is stated that the middle nasal concha and the inferior nasal concha region have a critical prescription in terms of sinus surgery. ${ }^{21}$ Evaluation of conchae is important in the treatment of such clinical conditions and also after treatment. Although there are many studies investigating the anatomical variations of nasal conchae, the studies which assess conchae dimensions are rare.

It is clinically important to know the proportions of the structures in the whole volume of the NC. There is only 1 study that shows the proportion of concha volumes in the whole NC volume. According to the study by Ertekin et al., ${ }^{7}$ the volume proportion of inferior nasal concha is in the range of $9-15 \%$ of the total volume of the NC. In the same study, the middle nasal concha volume proportion was reported in a range between 19$31 \%$ of the total volume of the NC. Despite the fact that the study by Ertekin et al. ${ }^{7}$ was conducted on children, the volume ratios of our study are similar.

This study revealed that the volume of the NC, nasal septum and conchae can be accurately calculated with the stereological method on the CBCT images. We believe that the data obtained in this study may assist clinicians in evaluating the treatment of pathological conditions related to the NC and in the planning of treatment as well preoperational and postoperational evaluations, especially in dentistry, otorhinolaryngology and plastic surgery.

\section{Limitations of the study}

In stereological studies, the statistical coefficient error is accepted as 0.05 or less. ${ }^{15}$ Similarly, the value of the coefficient error in the volumetric calculations is accepted as 0.05 or below in the present study. However, since the superior nasal concha can be detected in a few sections, the coefficient error of the volume of this structure is over than 0.05 , so superior nasal concha volume cannot be calculated.

\section{References}

1. Acer N, Bayar B, Başaloglu H, Oner E, Bayar K, Sankur S. Unbiased estimation of the calcaneus volume using the Cavalieri principle on computed tomography images. Ann Anat. 2008;190(5):452-460.

2. Acer N, Ertekin T, Küçük A, Babaoglu C, Cankaya MN, Camurdanoglu M. 20-25 Yaş Arası Sağlıklı Gençlerde Gri ve Beyaz Cevher Hacimlerinin Incelenmesi: Planimetrik Çalışma. Kocatepe Tıp Derg. 2008;9(2): 45-51.

3. Caprioglio A, Meneghel M, Fastuca R, Zecca PA, Nucera R, Nosetti L. Rapid maxillary expansion in growing patients: Correspondence between 3-dimensional airway changes and polysomnography. Int J Pediatr Otorhinolaryngol. 2014;78(1):23-27.

4. Cordasco G, Nucera R, Fastuca R, et al. Effects of orthopedic maxillary expansion on nasal cavity size in growing subjects: A low dose computer tomography clinical trial. Int J Pediatr Otorhinolaryngol. 2012;76(11):1547-1551.

5. El-Shazly AE, Poirrier AL, Cabay J, Lefebvre PP. Anatomic variations of lateral nasal wall. Clin Anat. 2012;25(3):340-346.

6. Emirzeoglu M, Sahin B, Celebi M, Uzun A, Bilgic S, Tontus HO. Estimation of nasal cavity and conchae volumes by stereological method. Folia Morphol (Warsz). 2012;71(2):105-108.

7. Ertekin T, Değermenci M, Nisari M, Unur E, Coşkun A. Age-related changes of nasal cavity and conchae volumes and volume fractions in children: A stereological study. Folia Morphol (Warsz). 2016;75(1): 38-47.

8. Ghoneima A, Imburgia A, Halum S, Vandis M, Kula K. Three-dimensional airway analysis of trumpet players vs non-trumpet players. Oral Radiol. 2015;31(2):105-113.

9. Guijarro-Martinez R, Swennen GR. Cone-beam computerized tomography imaging and analysis of the upper airway: A systematic review of the literature. Int J Oral Maxillofac Surg. 2011;40(11):1227-1237.

10. Gundersen HJG. Notes on the estimation of the numerical density of arbitrary profiles: The edge effect. J Microsc. 1977;111(2):219-223.

11. Gundersen HJ, Jensen EB. The efficiency of systematic sampling in stereology and its prediction. J Microsc. 1987;147(Pt 3):229-263.

12. Hodez C, Griffaton-Taillandier C, Bensimon I. Cone-beam imaging: Applications in ENT. Eur Ann Otorhinolaryngol Head Neck Dis. 2011; 128(2):65-78.

13. Kayipmaz S, Sezgin OS, Saricaoglu ST, Bas O, Sahin B, Küçük M. The estimation of the volume of sheep mandibular defects using cone-beam computed tomography images and a stereological method. Dentomaxillofac Radiol. 2011;40(3):165-169.

14. Kula K, Jeong AE, Stacey $H$, Kendall D, Ghoneima A. Three dimensional evaluation of upper airway volume in children with different dental and skeletal malocclusions. J Biomed Graph Comput. 2013; 3(4):116.

15. Mouton PR. Principles and Practices of Unbiased Stereology. Baltimore, MD: John Hopkins University Press; 2003:5-6.

16. Odaci E, Sahin B, Sonmez OF, Kaplan S, Bas O, Bilgic S. Rapid estimation of the vertebral body volume: A combination of the Cavalieri principle and computed tomography images. Eur JRadiol. 2003;48(3): 316-326.

17. Onuk B, Kabak M, Sahin B, Ince NG, Selcuk MB. New method for estimating the volume and volume fractions of the nasal structures in the goose (Anser anser domesticus) using computed tomography images. Br Poult Sci. 2013;54(4):441-446.

18. Ophir DE, Shapira AA, Marshak GS. Total inferior turbinectomy for nasal airway obstruction. Arch Otolaryngol. 1995;111(2):93-95.

19. Orhan I, Soylu E, Altın G, Yılmaz F, Çalım ÖF, Örmeci T. Paranazal sinüs anatomik varyasyonlarının bilgisayarlı tomografi ile analizi. Abant Medical Journal. 2014;3(2):145-149.

20. Patel RM, Pinto JM. Olfaction: Anatomy, physiology and disease. Clin Anat. 2014;27(1):54-60.

21. Santos RDP, Habermann W, Hofmann T, Stammberger H. Pre and post functional endoscopic sinus surgery nasal cavity volume assessment by acoustic rhinometry. Braz J Otorhinolaryngol. 2006;72(4): 549-553. 
22. Samoliński BK, Grzanka A, Gotlib T. Changes in nasal cavity dimensions in children and adults by gender and age. Laryngoscope. 2007; 117(8):1429-1433.

23. Scarfe WC, Farman AG, Sukovic P. Clinical applications of cone-beam computed tomography in dental practice. J Can Dent Assoc. 2006; 72(1):75-80.

24. Sharma S. Importance of treating compensatory hypertrophy of inferior turbinate in cases of septal deviation causing nasal obstruction. Journal of Otolaryngology ENT-Research. 2016;4(3):00097.

25. Smith T, Ghoneima A, Stewart K, et al. Three-dimensional computed tomography analysis of airway volume changes after rapid maxillary expansion. Am J Orthod Dentofacial Orthop. 2012;141(5):618-626.

26. Souza RP, Junior JPB, Tornin OS, et al. Sinonasal complex: Radiological anatomy. Radiologia. 2006;39(5):367-372.

27. Standring S, ed. Gray's Anatomy the Basis of Clinical Practice. $39^{\text {th }}$ ed. Barcelona, Spain: Elsevier Ltd.; 2005:547-561.
28. Starbuck JM, Friel MT, Ghoneima A, Flores RL, Tholpady S, Kula K. Nasal airway and septal variation in unilateral and bilateral cleft lip and palate. Clin Anat. 2014;27(7):999-1008.

29. Terheyden H, Maune S, Mertens J, Hilberg O. Acoustic rhinometry: Validation by three-dimensionally reconstructed computer tomographic scans. J Appl Physiol (1985). 2000;89(3):1013-1021.

30. Tso HH, Lee JS, Huang JC. Evaluation of the human airway using conebeam computerized tomography. Oral Surg Oral Med Oral Pathol Oral Radiol Endod. 2009;108(5):768-776.

31. White SC, Pharoah MJ. The evolution and application of dental maxillofacial imaging modalities. Dent Clin North Am. 2008;52(4):689-705.

32. Zeng J, Gao X. A prospective CBCT study of upper airway changes after rapid maxillary expansion. Int J Pediatr Otorhinolaryngol. 2013; 77(11):1805-1810 